\title{
Entrepreneurial Education Embedded in Sport Psychology: A Swedish Case Study
}

\author{
Stefan Holmström (Corresponding author) \\ Department of Psychology, Faculty of Social Science, Umeå University \\ S-90187 Umeå, Sweden \\ Tel: 469-0786-6044 E-mail: Stefan.holmstrom@umu.se \\ Erik Lindberg \\ Umeå School of Business and Economics, Faculty of Social Science, Umeå University \\ S-90187 Umeå, Sweden
}

Tel: 469-0786-5058 E-mail: erik.lindberg@umu.se

John Jansson

Department of Psychology, Faculty of Social Science, Umeå University

S-90187 Umeå, Sweden

Tel: 469-0786-7834 E-mail: john.jansson@umu.se

Received: September 29, 2015 Accepted: October 21, 2015 Published: November 20, 2015

doi:10.5296/jet.v3i1.8374 URL: http://dx.doi.org/10.5296/jet.v3i1.8374

\begin{abstract}
The main objective of this study was to provide a contribution to the entrepreneurship education field through evaluating and describing changes in students' attitudes towards entrepreneurship. A pre-test and post-test design was used to evaluate a course design where sport psychology was the main topic with an embedded element of entrepreneurship education. The course was part of university program in Masters Programme in Sports Psychology or Physical Trainer Programme. Sport psychology-students are not the traditional group of students that are selected and trained to get both skills and a positive entrepreneur mindset. There were 39 students completing both the pre-test and post-test questionnaire (response rate $84.4 \%)$, mean age 23 years $(\mathrm{SD}=2.90)$. Both the pre- and post-test results showed that the sport psychology students had positive attitudes towards entrepreneurship, and the embedded course design have significant effect on students' subjective perception of their ability to create and commercialize new ideas. The results from this case study shown that an embedded course design with sport psychology and entrepreneurial education make it possible to strengthen students' entrepreneurial attitudes. The positive results point out that it is important to continue examine embedded coursed designs between entrepreneurial education and non-traditional areas (e.g., physiotherapists, dentists, architects, e.g.).
\end{abstract}

Keywords: Entrepreneurship education, embedded, entrepreneurship attitudes, self-directed learning, opportunity recognition, course design, business plans 


\section{Introduction and Background}

Already when Porter (1990) published the "The Competitive Advantage of Nations" was the awareness of increasing global completion highlighted. The Global competition forced international companies to develop different strategies, and strategies focusing on restricting, reengineering, downsizing to become lean and agile (Thonberry, 2003). At the same time did the conditions for companies in the domestic market and the labor market change. Individuals could no longer look for secure lifetime employment after their exam in the same degree as earlier. People as well as companies had to become more flexible, innovative and proactive to be successful in dealing with this new situation.

One strategy that has quickly become a successful weapon for companies in a competitive environment is corporate entrepreneurship (Thonberry, 2003). A common view in today's global market is that entrepreneurship generates employment, economic wealth and competiveness. Such positive effects are evident from start-ups of companies and from employees whose entrepreneurial acts make large established firms prosper. Promoting entrepreneurship is therefore viewed as a national priority by governments around the world (Fairliehe \& Holleran, 2012). Policy makers believe that new venture formation and more entrepreneurship contribute to higher levels of innovation, technology and economic grow (Oosterbeck, \& Van Praag, 2010; Von Graevenitz, Harhoff, \& Weber, 2010).

The need to support entrepreneurial activities has also been recognized at EU level where the Commission launched a policy in 2005 to support the development of an entrepreneurship culture. The European Youth Pact adopted by the European Council 2005 is thus an example of a policy initiative to promote an entrepreneurial culture. As such this policy aimed at providing students with basic entrepreneurial and business skill (European Commission, 2006). Europe needs to stimulate the mindsets of young people and the growth of small and medium-sized enterprises (European Commission, 2008). Themes that are of current interest throughout Europe are development and promotion of entrepreneurship and entrepreneurship education (McCoshan, 2010). Policymakers have also recognized the importance of education in entrepreneurship as entrepreneurial activities are regarded as key drivers of economic growth (Fayolle, 2013; Rideout \& Gray, 2013). In Horizon 2020 does the new EU strategy emphasizes the importance of bringing new ideas to the market and promote more entrepreneurial culture. One way of doing this is to incorporate entrepreneurship education in the existing curricula (Cotoi, Bodoasca, \& Cotoi, 2011). Entrepreneurship, in general, is also proving increasingly popular in business schools, universities and other educational institutions (Fayolle, 2013). The trend is clear; the number of courses and programs has increased in response to the growing demand for such education (Pittaway \& Cope, 2007).

Entrepreneurship education is one in which many stakeholders have high expectations (European Commission, 2006). One actor that has taken this challenge and started to work with the task is the universities' (Etzkowitz et al., 2001) and the number of courses and programs has expanded significantly (Matley \& Carey, 2006). Numerous of studies witness of the progress and the state of entrepreneurship education (e.g., Kurato, 2005; Pittway \& Cope, 2007; Solomon, Duffy, \& Tarabishy, 2002). However, the programs are often 
self-selected and last for six month or more, and are mostly aimed for business students. There is a lack of courses and studies focusing on other categories of students. However, there's a gap in the field with few courses that are held for just five weeks full time and are mandatory at the undergraduate level, which excludes the self-selection bias, which influence several studies (Rideout \& Gray, 2013). According to Pittaway and Edwards (2012) there are few courses, programs and studies of entrepreneurship education in embedded environments for non-business students, and there are no studies regarding entrepreneurship education and psychology students.

To sharpen the focus further, this study conduct the design and impact of the only course to our knowledge where sport psychology students are prepared for the new era where, entrepreneurship is important. The sport psychology students are prepared for a future career in health and/or competitive settings (Carless \& Prodan, 2003), and skills in entrepreneurship education are important for both the individuals choosing work in an organization or as self-employed. The labor market for a carrier in sport psychology is growing, and is characterized by competition and there is a need for people applying entrepreneurship attitudes and skills.

This paper is a small step in that direction with its focus on how education can be structured, evaluated and which impact it has on student's attitudes. There is a lack of empirical verifications regarding the impact of embedded entrepreneurship education, and its impact on the student's attitude towards entrepreneurship. The aim of this paper is to describe how the department of Psychology at Umeå University collaborated with the local Business School to develop and manage one course in education of sport psychology to meet these new challenges and the influence it has on the student's attitudes that will become our future managers.

\section{Entrepreneurship Education}

\subsection{Background or Literature Review}

Three different forms of entrepreneurship education have historically been highlighted; these are "About", "For" and "Through" (Gibb, 2002; Handscombe, Kothari, Rodriguez-Falcon \& Patterson, 2008; Pittaway \& Cope, 2007; Pittaway, Hannon, \& Gray, 2009). "About" emphasizes on what entrepreneurs do, and why entrepreneurs are needed. The focus of the "For" form lies on entrepreneurial behavior and skills, and the "Through" form has it focus on creating entrepreneurial mindset and attitudes besides getting the students to understand the nature of the relationships they need to develop with important stakeholders.

The conventional way to teach students about entrepreneurship was done in a traditionally deductive way with one-way communication, aiming to raise awareness or share knowledge (Pittaway \& Hanlon, 2008). When the goal started to change and the "for" form become emphasized, the approach to teach student also changed. The movement was towards preparing the students for acting and they learnt more skills to become competent to meet current issues in the business world they soon would be a part of. This category is dominated by an inductive approach facilitating a creation of skills from the environment in which they 
later shall be applied. The students often became engaged in different tasks, activities or projects with a practical orientation that facilitate a learning of core skills and competencies (Solomon et. al, 2002). However, there are several scholars that point out the mix between them that were common and still exists in courses or programs. Jones and Gibbs (2004) point out the difference between entrepreneurship education that is similar to small business management education and entrepreneurship education that emphasize the need to create opportunity-seeking individuals. The current trend is that the classical question if entrepreneurship can be taught is out of date, it has changed to "How should it be taught?" (DeTienne \& Chandler, 2004; Kuratko, 2005).

It provides non-business students experience of entrepreneurship closely connected to their discipline. It makes them motivated to learn what they experience as relevant knowledge for their future career. Mwasalwiba (2010) mean that there is an increasing attention for impact assessment and which methods that are most suitable to reach an impact and measure change in some pre-determined variables among students. A group of indicators has been penetrated in the scholarly debate about how to measure impact and they originate from psychological constructs i.e. different attitudes and perceptions. According to Fayolle, Gailly and Lassas-Clerc (2006) it is obviously that the trend is moving towards influencing the behavioral mindset and cultural view of entrepreneurship.

The third wave of entrepreneurship education overlaps the "for" approach and also use the "learning by doing" pedagogy and is also known as "Through". Pittaway et al (2009) mean that it includes an application that has been taken the education a little bit further and is labeled as the "embedded" or "in" approach. This form is usually embedded within courses focused on other disciplines or subjects, for example, by combining an academic discipline (e.g., social science) and entrepreneurial education to form and create new ideas for practical application in different or new domains. The purpose is to give students, within non-business subjects, awareness and experience of entrepreneurship that is relevant for their field of interest (Pittaway \& Edwards, 2012). The three forms (about, for, and through) can be used, but they will be embedded within a course focused on a different discipline (Pittaway et al. 2009).

In line with Pittaway and colleagues $(2009 ; 2012)$ the curriculum for the current course had an embedded design, combing sport psychology and entrepreneurial education for students on mandatory sport psychology course in their program. Entrepreneurship education is defined by Shane as an activity that includes the discovery, evaluation and exploitation of opportunities. These can later be developed in to introduce new services, products, and ways of organizing, markets, process, and raw material through organizing (Shane \& Ventakaraman, 2000; Shane, 2012). This indicates that the main purpose for the entrepreneur is to create and identify new opportunities, but also implement them in uncertain environments (Neck \& Greene, 2011; Shane \& Ventakaraman, 2000). The curriculum is inspired by Fayolle (2006) pedagogical approach for entrepreneurial education and aim to develop entrepreneurial attitudes, skills, and personal qualities, which are designed to empower individuals with the necessary tools to implement ideas and initiate a new business. 
We are inspired by Thonberry (2003) and convinced that identifying and shaping ideas can be learned and this has influenced the pedagogy of the course. This means that the teaching methods should not just transfer knowledge, but contributes to the development of entrepreneurial skills and attitudes. This is in line with Gibb (1993) who suggests adoption of a focus on life experience, on action (pragmatic/intuitive model) and on ideas (reflexive/intuitive mode). Like Neck and Greene (2011) we propose an overarching framework for teaching that will require many different approaches to teaching and learning. The method requires practice. This comes natural when entrepreneurship is thought as a process - a process - of identifying an opportunity, understanding resource requirements, planning and implementing.

\subsection{Design of the course (curriculum pedagogy and methods and teaching technics)}

1770 was the first chair of pedagogy founded in University of Hall in Germany and 1951 was Coleman Foundation established with major focus on entrepreneurship education (Mueller, 2011). However, when Mwasalwiba (2010) made a review the majority of articles have disputed the use of traditional teaching methods that still was the most frequently used approach. According to both Fayolle and Griffiths with colleagues (Fayolle et al. 2006; Griffiths, Kickul, Bacq, \& Terjesen, 2012) little attention has been directed towards program design and pedagogical approaches and Mueller (2011) argue that it is important to study what impact different course design and teaching methods have. Mwasalwiba (2010) report that there are many disagreements over teaching methods and during his review of 21 scientific journals he identified twenty-six different methods. Pittaway and Edwards (2012) report that there is little existing research on what entrepreneurial educators "do" when engaging assessment.

Our definition of entrepreneurship requires an active-based action learning approach. The lecturer has to facilitate learning and stimulate self-discovery, not to exercise control. In line with Neck and Green (2011) the facilitator has to be aware of that the learning process is not predicable and it requires a lot of practice. The practice demands a reflection-in-practice to create deep learning and therefore we apply the construct of self-directed learning. It includes a learning process where the individuals are in control of the initiative and are able to determine their own learning needs and goals and to identify their competence as what skills they are lacking of. It is oriented towards the learner and for the individual it means planning, monitoring and evaluating the process. However, this does not appear by itself and it to be encouraged by us as a facilitator to apply the necessary steps in the right order starting with establish goals, activation of motivational structures and organizing the learning environment (Simanica \& Traistaru, 2013). During the course we apply active methods that require the instructor to facilitate learning and apply methods that enable student's self-discovery (Bennet, 2006; Jones \& Iredale, 2010; Leffler, 2008, Mueller, 2011).

The course contains literature, instructions and assignments that have expected learning outcomes regarding sport psychology and in embedded parts focusing on how it should be applied with the part focusing on entrepreneurship. One of the aims and the main point is that the student shall get more positive attitudes regarding opportunity recognition, develop and 
implement them in the area of their expertise. To put this in a more straight way we encourage the students to get the required knowledge and skills to create and develop business ideas with instructions to commercialize or implement their knowledge. In line with the self-directed learning approach the course starts with exercises to stimulate their attitudes and skill to apply creativity. The student gets different assignments and open-ended problems to solve in groups. This is managed with a problem based approach so the students will be prepared for the last assignment which is to find an opportunity that can be transformed into a business idea by using experimental and experience based learning in practice. The educator manages this phase by a coaching-style where there is no objective right and wrong and sees failure as a source for further development. Finally, the process ends by writing a business plan and to prepare an oral presentation. The presentation is done for professional business people that focus their external feedback on the business idea, but also give the students some advice regarding the business plan. Using business plans can according to Neck and Green (2011) be questioned, because the focus is towards investors and the work with it can become an administrative assignment and counteracts creativity. Maritz and colleagues (2010) argue that it is not an entrepreneurial approach and a facilitator has to consider this and use business plans in a more non-formal way and in a late stage of the business idea development process.

\section{Method}

\subsection{Design and Participants}

Using self-reported questionnaires measuring attitudes towards entrepreneurship, a pre-test and post-test design was used to evaluate a course design with an embedded design consistent of both entrepreneurship and sport psychology. The course is a mandatory part of university program in Masters Programme in Sports Psychology or Physical Trainer Programme at Umeå University. The course lasts for five weeks. All participants are university students on the third semester of their university program. A total of 39 students responded to both the pre-test and post-test measures. The response rate for the sample was $84.8 \%$. The age of the students varied between 19 and 30 years of age (Mean age $=23, \mathrm{SD}=2.90$ ), the gender breakdown being $64.1 \%$ men and $35.9 \%$ women.

\subsection{Instruments}

In this study, parts of a questionnaire earlier used in a study with similar aim as the present study will be used (Lindberg, Boman, Branberg, \& Wilson, submitted for publication). The original questionnaire consisted of 26 items measuring different aspects of entrepreneurship (e.g., entrepreneurial orientation, risk-taking inclination, opportunity recognition and general attitude to entrepreneurship and innovative mindsets), each item is rated on a seven point Likert-scale anchored on "Not at all applicable" to "Very applicable". From this questionnaire nine items was selected to evaluate the actual course, and answering the research question. The actual items measures aspects of entrepreneurial orientation, opportunity recognition and general attitude to entrepreneurship and innovative mindsets.

\subsection{Procedure and Analysis}

The data collection took place at the first and last day of the course (length of the course was 
five weeks). The same questionnaire were distributed to the students at both times, the questionnaire took approximately five minutes to complete. The participants were informed about the purpose of the study and informed consent was obtained.

Screening of the dataset and analysis of missing values was conducted following Tabachnich and Fidell (2007) recommendations, and missing data was determined to be missing at random. The Expectation-Maximization algorithm was used when missing data was imputed. To analyse the pre- and post-test rating of attitudes towards entrepreneurship made by students, multiple sets of paired-samples t-test were conducted. All data analyses were conducted utilizing IBM SPSS Statistics version 23.0.

\section{Results}

Means, standard deviations, and paired t-test of the pre- and post-test rating of student's attitudes towards entrepreneurship are presented in Table 1 . When examining the mean values, an overall trend is that the mean values of both the pre-test and post-test is generally high, some mean values are close to five, or over five on a Likert scale going from 1 to 7 with a range from "Not at all applicable" to "Very applicable". On a seven point Likert scale 3.5 represents the perceptual midpoint, and all mean values are above this perceptual midpoint.

Another trend that can be spotted with five of nine items having higher ratings on the post-test, but only two of these items shows a statistically significant changes between preand post-testing. The items which shows significant change at the .05 level are "My ability to create new products or services is very good", and "I feel that my ability to commercialize a new idea is very good". On the other hand two items have ratings going in the opposite direction, and have lower mean values on post-testing. These items are "I am ready to jump on unexpected opportunities", and "I can see myself as self-employed in the future" have ratings which are lower on the post-test. Notable is that both these items have mean values over five on the pre-test, and at the post-test measure still have high mean values. Two items show no, or very little change between the measurement points.

Table 1. Means (M), standard deviations (SD), and paired t-test (t)

\begin{tabular}{lcccccc}
\hline & \multicolumn{3}{c}{ Pre-test } & \multicolumn{3}{c}{ Post-test } \\
\cline { 2 - 6 } & M & SD & M & SD & t \\
\hline 1. I am ready to jump on unexpected opportunities & 5.26 & 1.41 & 5,00 & 1.39 & 1.61 \\
2. I always try to find new ways to implement things & 4.61 & 1.17 & 4.63 & 1.32 & -0.10 \\
3. I often find opportunities I realize & 4.22 & 1.46 & 4.33 & 1.07 & -0.52 \\
4. I think entrepreneurship is important & 5.39 & 1.46 & 5.32 & 1.28 & 0.32 \\
5. My ability to find new business ideas are very good & 3.87 & 1.74 & 4.18 & 1.39 & -1.28 \\
6. My ability to create new products or services is very good & 3.76 & 1.62 & 4.21 & 1.14 & $-2.04^{*}$ \\
7. I feel that my ability to think creatively is very good & 4.54 & 1.71 & 4.64 & 1.44 & -0.40 \\
8. I feel that my ability to commercialize a new idea is very good & 3.71 & 1.59 & 4.26 & 1.31 & $-2.49^{*}$ \\
9. I can see myself as self-employed in the future & 5.23 & 1.74 & 4.92 & 1.69 & 1.17 \\
\hline
\end{tabular}

Note: $\mathrm{n}=39 ; * \mathrm{p}<.05$. 


\section{Discussion}

The main objective of this study was to provide a contribution to the entrepreneurship education field through describing and evaluating an embedded course design for university students. The main topic of the course was sport psychology with an element of entrepreneurship education embedded in the course, and one of the examination assignments was a combination of sports psychology and entrepreneurship project. The course were relative short, and went on for five weeks with a breakdown of the total teaching time of the course, with 70 per cent of the time spent on focusing on sport psychology and 30 percent of the teaching time spent on entrepreneurship education. The pedagogical framework is student-orientated, and is based on self-directed learning where the students in small groups (2-3 students) creates business ideas and plans, by applying theories into practice through combining concepts from both sport psychology and entrepreneurship. The business-plans are presented for professional business developers so that they can give relevant feedback to the students. The roll of the educator is to support different ideas during the work process by using a coaching-style, and by supporting the student's ideas and initiatives. The students on the course were not selected for their interest in entrepreneurship because it was mandatory, the students were studying on a course in sport psychology. To our knowledge this is the only course to combing sport psychology and entrepreneurship at university level, and in our ambition to develop and evaluate the current course we have used a questionnaire as a complement to the traditional course evaluation. The questionnaire was used to evaluate students' attitudes towards entrepreneurship. Even if this student group's main area was not entrepreneurship, the result showed high mean-values on the pre-test indicating that the students had positive attitudes towards entrepreneurship (see Table 1) and in line with other embedded courses they have become strengthened (Pittaway \& Edwards, 2012).

The results show that the embedded course design have significant effect on students' subjective perception of their ability to create and commercialize new ideas, despite the element of entrepreneurship only consisted of one third of the lecture time on the course. These abilities are important for those students that consider starting and running businesses themselves in the future. However, the purpose of the course was not only to prepare the students for a career as self-employed, but also as managers and co-workers with an entrepreneurial mindset. Companies are living in an environment characterized by tough competition and need individuals with ability to create and commercialize new ideas. Sport psychology-students are not the traditional group of students that are trained for getting both skills and a positive entrepreneur mindset. However, these factors are important to possess in the future labor market and support corporate entrepreneurship and in line with Thornberry (2003). The results show that the students are prepared for making a contribution as managers in a competitive environment in the future as many stakeholders have expected from entrepreneurship education (EU Commission 2006, 2008).

The results also show that the embedded course design influences the student's attitudes towards jumping on unexpected opportunities. Even if the change is not significant it indicates that the students are not ready to act upon sudden opportunities in the same degree after the course as before. The results indicate that the students desire to see themselves as 
self-employed has reduced marginally. This can be seen as a negative consequence of the course. However, it can suggest a more realistic view of what it requires to be self-employed and is in line with the conclusions from von Graevenitz et al. (2010). This can be positive because the students need to reflect over opportunities before acting on them. Even if it can be beneficial for a country that there are many start-up companies, failing firms can be a costly real-world experience for the individual and for those involved in a bankruptcy.

The results from this case study can't be generalized, however do the results from the actual study show that an embedded course design have an effect on attitudes. In our strive to improve the actual course so it affects the students attitudes even more we believe some changes can be made. One is to change the mix and conduct a different breakdown on teaching time, with more time devoted to entrepreneurship because some further core lectures and exercises would be managed which could support their learning-process. Another change is to design the course over a longer period (e.g., give the course on ten weeks with half-time studies). The process to go from generating ideas to a complete business-plan is always time-consuming and for a rookie this means a very intense work at the same time as their studies in psychology progress. A longer timespan would facilitate greater possibilities to fulfill their business-plans and to reflect over different choices and possible consequences. Since it takes longer time for students in sport psychology which are not used to think about, and do not have the skills that is required for this job they have to build it simultaneously. The quality of the learning process could increase if it became less intense. As facilitators we have witnessed a number of student groups that have used their creativity and combined theories from the psychology field into business-ideas. With the current time span of the course it's important to come up with a business-idea early in the course, and this influence some students negatively so they experience stress. A longer course design will reduce this problem, and it will give the students more time to make the first phase of the creative process more fruitful. If more time was devoted for the first phase it will give the students greater possibilities to reflect and evaluate different ideas before deciding upon which option to execute. We believe that this alternative will give the students opportunities to create deeper knowledge and also strengthen the influence of attitudes towards entrepreneurship.

This case study is not without limitations. One limitation is that the current study is focused on one group in one course and the design is lacking of a control group to evaluate the changes in attitudes towards entrepreneurship. A control group would reduce the discussion of bias. Another weakness is the lack of follow-up measurement; it would be beneficial to follow how attitudes evolve over time. The aim of this study was to evaluate students' attitudes towards entrepreneurship, and the questionnaire meet the aim of the study, but before an expended study is planned, the questionnaire needs to be further developed and validated in similar contexts.

\section{Conclusions}

This case study has shown that an embedded course design with sport psychology and entrepreneurial education make it possible to strengthen students entrepreneurial attitudes. It has become apparent that accumulated knowledge in the actual area (scholarly community) 
needs to be expanded. It is important that the scholarly community takes the challenge and carry out more studies in the future. The positive results point out that it is important to continue examine embedded coursed designs between entrepreneurial education and non-traditional areas (e.g., physiotherapists, dentists, architects, e.g.).

\section{References}

Bennet, M. (2006). Business lectures' perception of the nature of entrepreneurship. International Journal of Entrepreneurial Behavior \& Research, 12, 165-188. doi: 10.1108/13552550610667440

Carless, S. A., \& Prodan, O. (2003). The impact of practicum training on career and job search attitudes of postgraduate psychology students. Australian Journal of Psychology, 55, 89-94. doi: 10.1080/00049530412331312944

Cotoi, E., Bodoasca, T., \& Cotoi, I. (2011). Entrepreneurship European development strategy in the field of education. Procedia-Sicial and Behavioral Sciences, 15, 3490-3499.

DeTienne, D. R., \& Chandler, G. N. (2004). Opportunity identification and its role in the entrepreneurial classroom: A pedagogical approach and empirical test. Academy of Management Learning and Education, 3, 242-257.

Etzkowitz, H. (2001). The Second Academic Revolution and the Rise of Entrepreneurial Science. IEEE Technology and Society, 22, 18-29.

European Commission. (2006). Implementing the Community Lisbon Programme: Fostering Entrepreneurial Mindsets through Education and Training. COM (2006) 33 Final Commission of the European Communities, Brussels.

European Commission. (2008). Entrepreneurship in higher education, especially within non-business studies. Brussels: Final Report of the Expert Group, Enterprise and Industry, EC, March.

Fairlie, R. W., \& Holleran, W. (2012). Entrepreneurship training, risk aversion and other personality traits: Evidence from a random experiment. Journal of Economic Psychology, 33, 366-378. http://dx.doi.org/10.1016/j.joep.2011.02.001

Fayolle, A. (2006). Evaluation of entrepreneurship education: Behaviour performing or intention increasing? International Journal of Entrepreneurship and Small Business, 2, 89-98.

Fayolle, A. (2013). Personal views on the future of entrepreneurship education. Entrepreneurship \& Regional Development: An International Journal, 25, 692-701. http://dx.doi.org/10.1080/08985626.2013.821318

Fayolle, A., Gailly, B., \& Lassas-Clerc, N. (2006). Assessing the impact of entrepreneurship education programs: A new methodology. Journal of European Industrial Training, 30, 701-720. http://dx.doi.org/10.1108/03090590610715022

Gibb, A. A. (1993). The Enterprise Culture and Education. Understanding Enterprise Education and its Links with Small Business Entrepreneurships and Wider Educational Goals. 
International Small Business Management Journal, 11, 11-34. http://dx.doi.org/10.1177/026624269301100301

Gibb, A. A. (2002). Creating conducive environments for learning and entrepreneurship. Industry and Higher Education, 16, 135-148. http://dx.doi.org/10.5367/0000000021012 96234

Griffiths, M., Kickul, J., Bacq, S., \& Terjesen, S. (2012). A dialogue with William J. Baumol: insights on entrepreneurship theory and education. Entrepreneurship: Theory and Practice, 36, 611-625. http://dx.doi.org/10.1111/j.1540-6520.2012.00510.x

Handscombe, R. D., Rodriguez-Falcon, E., \& Patterson, E. A. (2008). Embedding enterprise in science and engineering departments. Education \& Training, 50, 615-625. http://dx.doi.org/10.1108/00400910810909063

Jones, B., \& Iredale, N. (2010). Enterprise education as pedagogy. Education + Training, 52, 7-19. http://dx.doi.org/10.1108/00400911011017654

Kuratko, D. F. (2005). The Emergence of Entrepreneurship Education: Development, Trends, and Challenges. Entrepreneurship Theory and Practice, 29, 577-598. http://dx.doi.org/10. 1111/j.1540-6520.2005.00099.x

Leffler, E. (2008). The Many Faces of Entrepreneurship: A Discursive Battle for the School Arena. European Educational Research Journal, 1, 104-116. http://dx.doi.org/10.2304/ eerj.2009.8.1.104

Lindberg, E., Boman, H., Branberg, K., \& Wilson, T. (submitted for publication). Establishing an Entrepreneurial Mindset: A Swedish experience.

Maritz, P. A., Brown, C., \& Shieh, C. J. (2010). A blended learning approach to entrepreneurship education. Scientific Economics Journal: Special Edition, Actual Problems of Economics, 12, 83-93.

Matlay, H., \& Carey, C. (2007). Entrepreneurship education in the UK: a longitudinal perspective. Journal of Small Business and Enterprise Development, 14, 252-263. http://dx.doi.org/10.1108/14626000710746682

McCoshan, A. (2010). Towards Greater Cooperation and Coherence in Entrepreneurship Education. Report and Evaluation of the Pilot Action High Level Reflection Panels on Entrepreneurship Education initiated by DG Enterprise and Industry and DG Education and Culture. European Commission Directorate-General for Enterprise and Industry. Birmingham, UK: Vincent House.

Mueller, S. (2011). Increasing Entrepreneurial Intention: Effective Entrepreneurship Course Characteristics. International Journal of Entrepreneurship and Small Business, 13, 55-74. http://dx.doi.org/10.1504/IJESB.2011.040416

Mwasalwiba, E. S. (2010). Entrepreneurship education: a review of its objectives, teaching methods, and impact indicators. Education + Training, 52, 20-47. http://dx.doi.org/10.1108/ 
00400911011017663

Neck, H. M., \& Greene, P. G. (2011). Entrepreneurship Education: Known Worlds and New Frontiers. Journal of Small Business Management, 49, 55-70. http://dx.doi.org/10.1111/j. 1540-627X.2010.00314.x

Oosterbeck, H., \& Van Praag, M. (2010). Impact of entrepreneurship education on entrepreneurship skills and motivation. Journal of European Economic Review, 54, 442-454. http://dx.doi.org/10.1016/j.euroecorev.2009.08.002

Pittaway, L., \& Cope, J. (2007). Entrepreneurship education; a systematic review of the evidence. International Small Business Journal, 25, 479-510. http://dx.doi.org/10.1177/02662 42607080656

Pittaway, L., \& Edwards, C. (2012). Assessment: examining practice in entrepreneurship education. Education + Training, 54, 778-800. http://dx.doi.org/10.1108/00400911211274882

Pittaway, L., \& Hannon, P. (2008). Institutional strategies for developing enterprise education: a conceptual analysis. Journal of Small Business and Enterprise Development, 15, 202-226. http://dx.doi.org/10.1108/14626000810850937

Pittaway, L., Hannon, P., \& Gray, O. D. (2009). Assessment practice in enterprise education. International Journal of Entrepreneurial Behavior \& Research, 15, 71-93. http://dx.doi.org/10.1108/13552550910934468

Porter, M. E. (1990). The Competitive Advantage of Nations. New York: Free Press.

Rideout, E., \& Gray, D. O. (2013). Does Entrepreneurship Education Really Work? A Review and Methodological Critique of the Empirical Literature on the Effects of University-Based Entrepreneurship Education. Journal of Small Business Management, 51, 329-351. http://dx.doi.org/10.1111/jsbm.12021

Shane, S., \& Venkatraman, S. (2000). The promise of entrepreneurship as a field of research. Academy of Management Review, 25, 217-226.

Shane, S. (2012). Reflections on the 2010 AMR Decade Award: Delivering on the Promise of Entrepreneurship as a Field of Research. Academy of Management Review, 37, 10-20. http://dx.doi.org/10.5465/amr.2011.0078

Simanica, M., \& Traistaru, A. (2013). Self-directed learning in economic education. International Journal of Education and Research, 1, 1-13.

Solomon, G. T., Duffy, S., \& Tarabishy, A. (2002). The state of entrepreneurship education in the United States: A nationwide survey and analysis. International journal of Entrepreneurial Education, 1, 1-22.

Tabachnick, B. G., \& Fidell, L. S. (2007). Using Multivariate Statistics (5th ed). Boston: Allyn and Bacon.

Thornberry, N. (2003). Corporate Entrepreneurship: Teaching methods to be Entrepreneurs'. 


\section{Macrothink}

Journal of Management Development, 22, 329-344. http://dx.doi.org/10.1108/0262171031 0467613

Von Graevenitz, G., Harhoff, D., \& Weber, R. (2010). The effects of entrepreneurship education. Journal of Economic Behavior \& Organization, 76, 90-112. http://dx.doi.org/10.10 16/j.jebo.2010.02.015

\section{Copyright Disclaimer}

Copyright reserved by the author(s).

This article is an open-access article distributed under the terms and conditions of the Creative Commons Attribution license (http://creativecommons.org/licenses/by/3.0/). 